\title{
WT1 expression in salivary gland pleomorphic adenomas: a reliable marker of the neoplastic myoepithelium
}

\author{
Gerald Langman ${ }^{1}$, Claire L Andrews ${ }^{1}$ and Annikka Weissferdt ${ }^{2}$ \\ ${ }^{1}$ Department of Cellular Pathology, Birmingham Heartlands Hospital, Birmingham, West Midlands, UK and \\ ${ }^{2}$ Department of Pathology and Laboratory Medicine, MD Anderson Cancer Center, Houston, TX, USA
}

\begin{abstract}
Pleomorphic adenoma is a benign salivary gland neoplasm with a diverse morphology. This is considered to be a function of the neoplastic myoepithelium, which shows histological and immunophenotypical variability. Wilms' tumor 1 gene (WT1) protein, involved in bidirectional mesenchymal-epithelial transition, has been detected by reverse transcription PCR in salivary gland tumors showing myoepithelial-epithelial differentiation. The aim of this study was to investigate the immunoreactivity of WT1 in pleomorphic adenomas and to compare the pattern of staining with $\mathrm{p} 63$ and calponin, two reliable markers of myoepithelial cells. A total of 31 cases of pleomorphic adenoma were selected. The myoepithelium was classified as myoepithelial-like (juxtatubular and spindled), modified myoepithelium (myxoid, chondroid and plasmacytoid) and transformed myoepithelium (solid epithelioid, squamous and basaloid cribriform). Immunohistochemistry for WT1, p63 and calponin was assessed in each myoepithelial component, as well as in nonneoplastic myoepithelial cells and inner tubular epithelial cells. There was no immunostaining of tubular epithelial cells by any of the markers. In contrast to p63 and calponin, WT1 did not react with normal myoepithelial cells. Cytoplasmic WT1 staining was present in all pleomorphic adenomas, and in 29 cases $(94 \%),>50 \%$ of neoplastic myoepithelial cells were highlighted. p63 and calponin stained the myoepithelium in 30 tumors. In comparison, 50\% of cells were positive in 21 $(68 \%)$ and $9(29 \%)$ cases of p63 and calponin, respectively. Staining with WT1 showed less variability across the spectrum of myoepithelial differentiation with the difference most marked in the transformed myoepithelium. WT1 is a sensitive marker of the neoplastic myoepithelial cell in pleomorphic adenomas. The role of this protein in influencing the mesenchymal-epithelial state of cells suggests that WT1 and the myoepithelial cell have an important role in the histogenesis of pleomorphic adenomas.

Modern Pathology (2011) 24, 168-174; doi:10.1038/modpathol.2010.190; published online 5 November 2010
\end{abstract}

Keywords: immunohistochemistry; myoepithelial cell; pleomorphic adenoma; salivary gland neoplasm; WT1

Pleomorphic adenoma is a benign salivary gland neoplasm with a diverse morphology due to the variable contributions of epithelial, myoepithelial and stromal components. Together with other salivary gland neoplasms, it shares dual luminal and abluminal differentiation, but it is the extracellular stroma that is the defining feature. This morphological plasticity is considered to be a function of the myoepithelial cell that, together with epithelial cells, represents the proliferative

Correspondence: Dr G Langman, Department of Cellular Pathology, Birmingham Heartlands Hospital, Bordesley Green East, Birmingham B9 5SS, UK.

E-mail: gerald.langman@heartofengland.nhs.uk

Received 13 April 2010; revised 11 August 2010; accepted 12 August 2010; published online 5 November 2010 component of pleomorphic adenomas. ${ }^{1}$ Usually the histological diagnosis is straightforward, but occasionally, other benign and malignant salivary gland neoplasms are difficult to exclude, even with the aid of ancillary tests.

In the salivary gland tissue, the normal myoepithelial cell is wedged between the luminal acinar and intercalated duct cells and the basement membrane. It is a modified epithelial cell with epithelial and smooth muscle differentiation reflected in the ultrastructure appearance and the immunohistochemical phenotype. Until recently, the perception was that its role in normal physiology was restricted to a contractile function. However, it is now recognized that it is involved in, among others, embryonic development, extracellular matrix synthesis and remodeling and paracrine 
signaling. ${ }^{2}$ A putative tumor-suppressor function has been suggested, and in the breast, the myoepithelial cell inhibits proliferation, angiogenesis and tumor cell invasion. ${ }^{3,4}$

The neoplastic myoepithelium is characterized by histological and immunohistochemical diversity. The variability or loss of immunoreactivity for some markers, most notably that of cytokeratin 14, and the expression of other markers generally absent in the normal myoepithelium (S100-protein, glial fibrillary acidic protein (GFAP), vimentin) ${ }^{2}$ is unique to neoplastic myoepithelial cells. This modification in the immunophenotypic expression is reflected in the different morphological and cytological alterations at a light microscopic level. Most of the described markers of the neoplastic myoepithelium are directed against structural components of cells. The potential immunohistochemical expression of a marker targeted against a molecular event in the neoplastic myoepithelium may shed light on the histogenesis and aid in the diagnosis of pleomorphic adenomas and other salivary gland neoplasms.

The transformation to a neoplastic myoepithelial cell must be accompanied by complex alterations in gene expression. Wilms' tumor-suppressor gene (WT1) has been detected by reverse transcription PCR in salivary gland tumors showing myoepithelial-epithelial differentiation. ${ }^{5}$ Immunoblot analysis confirmed increased protein expression, but neither the transcriptional or translational product was identified in the normal salivary gland. This suggests that WT1, a protein involved in bidirectional mesenchymal-epithelial transition, ${ }^{6}$ may have a role in cellular differentiation and tumorigenesis in pleomorphic adenomas.

The WT1 protein has been detected by immunohistochemistry in various tumors, but no study has investigated its expression in pleomorphic adenomas or in any other salivary gland tumor. ${ }^{7}$ Given the detection of WT1 mRNA and protein in neoplasms of the salivary gland, we hypothesized that the morphological diversity of pleomorphic adenomas may be explained by the expression of WT1 in the neoplastic myoepithelium. This study explores the immunoreactivity of WT1 in pleomorphic adenomas and compares this pattern of staining with p63 and calponin, two reliable markers of neoplastic myoepithelial cells. ${ }^{8,9}$

\section{Materials and methods}

\section{Tissue Samples}

A total of 31 cases of pleomorphic adenoma were selected from the paraffin wax-processed tissue archives of the Cellular Pathology Department at the Birmingham Heartlands Hospital from 2000 to 2009. Overall, 22 patients were female and 9 male. Their age ranged from 16 to 75 years with a median of 41.5 years. The majority of tumors were from the parotid gland (25) with 4 cases arising in the submandibular gland and 1 from the hard palate. The normal salivary gland tissue was included in 28 cases.

\section{Tissue Staining and Immunohistochemistry}

In each case, four 3- $\mu$ m-thick sections were cut from a representative block. One slide was stained with hematoxylin and eosin. Three slides were dried overnight in a $37^{\circ} \mathrm{C}$ oven and subsequently heated at $60^{\circ} \mathrm{C}$ for $15 \mathrm{~min}$. They were then stained with antibodies for WT1, p63 and calponin using a Ventana Benchmark XT automated stainer in conjunction with the Ultraview DAB detection kit (Table 1). On removal of the slides from the automated stainer, they were washed in soapy water, dehydrated, cleared and mounted in pertex mountant.

The immunohistochemical staining pattern was assessed in the different cell types of both the normal salivary gland tissue and the pleomorphic adenoma and scored semi-quantitatively as follows: $0=$ no cells stained; $1=<10 \% ; 2=10-50 \% ; 3=50-100 \%$.

\section{Results}

\section{Normal Salivary Gland Tissue}

In all 28 cases, in which the normal salivary gland tissue was included, there was no staining with WT1 of myoepithelial cells lining the acini or intercalated ducts, whereas basal cells of the striated and interlobular ducts were similarly negative. p63 uniformly stained myoepithelial and basal cells lining the acini and ducts. Only myoepithelial cells, and not basal cells, were highlighted by calponin. Neither WT1 or p63 nor calponin stained the luminal acinar and ductal cells.

Table 1 Specifications of antibodies used

\begin{tabular}{|c|c|c|c|}
\hline Antibody & $\begin{array}{l}\text { Antibody dilution } \\
\text { (in } P B S \text { buffer) }\end{array}$ & Antigen retrieval & $\begin{array}{c}\text { Antibody incubation } \\
\text { time (min) }\end{array}$ \\
\hline $\begin{array}{l}\text { WT-1 (Labvision, clone 6F-H2, } \\
\text { against the } \mathrm{N} \text { terminus) }\end{array}$ & $\begin{array}{l}\text { Ready to use, no } \\
\text { dilution required }\end{array}$ & $\begin{array}{l}\text { EDTA-based heat-induced treatment } \\
\text { for } 60 \mathrm{~min}\end{array}$ & 32 \\
\hline p63 (Labvision, clone 4A4) & $1: 150$ & $\begin{array}{l}\text { EDTA-based heat-induced treatment } \\
\text { for } 30 \mathrm{~min}\end{array}$ & 32 \\
\hline Calponin (Dako, clone CALP ${ }^{1}$ ) & $1: 250$ & Protease treatment for $4 \mathrm{~min}$ & 32 \\
\hline
\end{tabular}




\section{Pleomorphic Adenomas}

\section{Histological features}

Histologically, pleomorphic adenomas were characterized by tubular epithelial structures with inner tubular cells and a mantle of myoepithelial cells dispersed in a variable chondromyxoid matrix. The interface between the cellular islands and the stroma was poorly demarcated with myoepithelial cells of various architectural and cytological patterns radiating from the mantle and melting into the stroma. Of 31 tumors, 17 were predominantly myxoid and 14 cellular.

The classification of different myoepithelial cell types and growth patterns were based on previous studies. ${ }^{9,10}$ The myoepithelium-like juxtatubular and spindle cells surrounded the inner tubular epithelial cells. Spindle cells appear to gradually blend with the myxochondroid regions, which contain stellate and polygonal cells. Cells within the myxoid and cartilaginous areas together with plasmacytoid cells are termed 'modified myoepithelium'. The transformed myoepithelium refers to the solid sheets of epithelioid cells, squamous islands and cribriform/basaloid areas.

Table 2 Percentage of all myoepithelial cell types staining in pleomorphic adenoma

Number of tumors staining

\begin{tabular}{lcrrr}
\hline $\begin{array}{l}\text { Percentage of myoepithelial } \\
\text { cells staining }\end{array}$ & 0 & $<10 \%$ & $10-50 \%$ & $>50 \%$ \\
\hline WT1 & 0 & 0 & 2 & 29 \\
Calponin & 1 & 10 & 11 & 9 \\
p63 & 1 & 4 & 5 & 21 \\
\hline
\end{tabular}

Immunohistochemical analysis

The results of WT-1, p63 and calponin immunohistochemical staining are summarized in Tables 2 and 3. There was no immunostaining of inner tubular epithelial cells by any of the markers (Figure 1).

Of 31 tumors, 30 showed staining of myoepithelial cells with calponin and p63. However, especially with calponin, the staining was patchy with 10 of 31 tumors (32\%) showing expression in fewer than $10 \%$ of myoepithelial cells. In contrast, p63 showed more uniform staining and more than half of the myoepithelial cells were highlighted in 21 pleomorphic adenomas (68\%). Of the different cell types, myoepithelial-like cells were more uniformly expressed (Figure 2), and this was better demonstrated with p63 than with calponin. Calponin was identified in myxoid cells of the modified myoepithelium, whereas plasmacytoid and chondroid cells were either negative or showed immunoreactivity in very few cells. More of the modified myoepithelium was highlighted by p63, but in most cases, fewer than $50 \%$ of the cells were positive. There was no immunoreactivity of the transformed myoepithelium with calponin. p63 was positive in the squamous nests. However, staining in epithelioid sheets, when positive, was patchy. The single case with cribriform differentiation was not highlighted by p63.

There was immunoreactivity of myoepithelial cells for WT1 in all pleomorphic adenomas. When compared with calponin and p63, the staining was more uniformly positive with 29 tumors (94\%) showing expression in $>50 \%$ of myoepithelial cells. In the other 2 tumors, between 10 and $50 \%$ of the neoplastic myoepithelium was positive. With few exceptions, the different cell types were consistently expressed with $>50 \%$ positive in many cases (Figures 3 and 4). No staining was observed in

Table 3 Expression of WT1, calponin and p63 in the different cell types of pleomorphic adenoma

\begin{tabular}{|c|c|c|c|c|c|c|c|c|c|c|c|c|c|}
\hline \multirow[t]{2}{*}{ Cell type } & \multirow[t]{2}{*}{ Number of cases } & \multicolumn{4}{|c|}{ WT1 } & \multicolumn{4}{|c|}{ Calponin } & \multicolumn{4}{|c|}{$p 63$} \\
\hline & & $O$ & 1 & 2 & 3 & 0 & 1 & 2 & 3 & $O$ & 1 & 2 & 3 \\
\hline Inner tubular & 31 & 31 & 0 & 0 & 0 & 31 & 0 & 0 & 0 & 31 & 0 & 0 & 0 \\
\hline \multicolumn{14}{|l|}{ Myoepithelium-like } \\
\hline Outer tubular (cuboidal) & 31 & 0 & 0 & 2 & 29 & 5 & 13 & 7 & 6 & 2 & 3 & 9 & 17 \\
\hline Spindle & 23 & 0 & 0 & 6 & 17 & 16 & 0 & 4 & 3 & 5 & 4 & 6 & 8 \\
\hline \multicolumn{14}{|l|}{ Modified myoepithelium } \\
\hline Myxoid & 24 & 0 & 0 & 6 & 18 & 1 & 8 & 6 & 9 & 2 & 6 & 12 & 4 \\
\hline Chondroid & 4 & 0 & 1 & 0 & 3 & 3 & 0 & 1 & 0 & 2 & 0 & 2 & 0 \\
\hline Plasmacytoid & 20 & 1 & 0 & 3 & 16 & 7 & 9 & 0 & 4 & 3 & 4 & 6 & 7 \\
\hline \multicolumn{14}{|l|}{ Transformed myoepithelium } \\
\hline Epithelioid & 6 & 0 & 0 & 0 & 6 & 6 & 0 & 0 & 0 & 2 & 3 & 0 & 1 \\
\hline Squamous & 5 & 3 & 0 & 2 & 0 & 5 & 0 & 0 & 0 & 0 & 0 & 1 & 4 \\
\hline Cribriform (basaloid) & 1 & 0 & 0 & 0 & 1 & 1 & 0 & 0 & 0 & 1 & 0 & 0 & 0 \\
\hline
\end{tabular}

Intensity of staining: $0=$ no cells stained; $1=<10 \% ; 2=10-50 \% ; 3=50-100 \%$. 


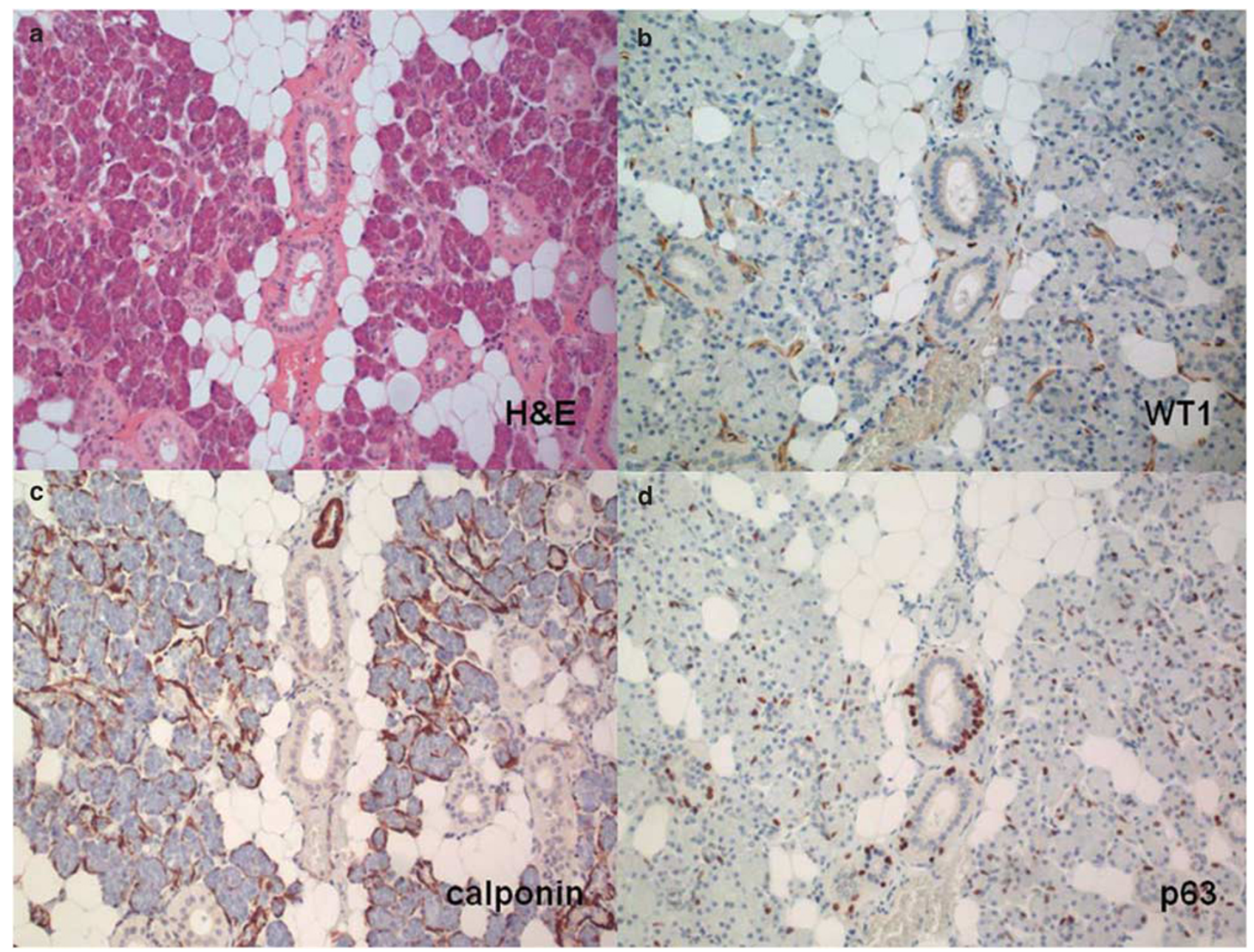

Figure 1 Hematoxylin and eosin-stained section of the normal salivary gland tissue (a) with absent WT1 staining of myoepithelial cells (b). The staining in endothelial cells acts as an internal control. Myoepithelial cells are decorated with calponin (c) and p63 (d) with additional staining of basal cells in panel $\mathbf{d}$.

plasmacytoid cells of one tumor, which showed strong immunoreactivity for calponin with fewer than $10 \%$ decorated by p63. In the transformed squamous areas, only two of five cases were positive and here the immunoreactivity was seen in peripheral cells of the squamous islands (Figure 5).

\section{Discussion}

Neoplasms of the salivary gland are histological complex tumors with a subset containing both epithelial and myoepithelial cells. The variable morphological appearance of pleomorphic adenomas, a tumor showing this dual luminal and abluminal differentiation, is attributed to the neoplastic myoepithelium.

The identification of the myoepithelial cell in salivary gland neoplasms is a useful adjuvant in their histological classification. However, the search for the ideal myoepithelial marker is complicated by the immunohistochemical diversity of the myoepithelial cell, a consequence of its variable morphological and ultrastructure appearance. Initially, S-100 protein, an acidic calcium-binding protein, was a popular marker. ${ }^{11}$ However, additional studies showed positive staining of ductal epithelial cells, limiting its specificity. ${ }^{12,13}$ Subsequent markers targeted the complex cytoskeleton of the myoepithelial cell. Results were limited with cytokeratin and vimentin also expressed in other neoplastic salivary gland cells, ${ }^{11,14}$ whereas staining with GFAP was variable and closely related to myxomatous and early chondromatous differentiation. ${ }^{15}$ Furthermore, staining with smooth muscle actin was frequently weak and, in pleomorphic adenomas, was mainly limited to the outer tubular myoepithelial cells. ${ }^{16}$ The introduction of novel smooth muscle markers was more encouraging, and calponin proved to be a more sensitive marker. ${ }^{9}$ Recently, p63 and maspin have been shown to stain both normal and neoplastic myoepithelial cells but neither are specific. ${ }^{8,17}$ Maspin was detected in the inner tubular epithelial cells of pleomorphic adenomas, whereas p63 was seen in the basal cells of basal cell adenomas and in the squamous cells of 


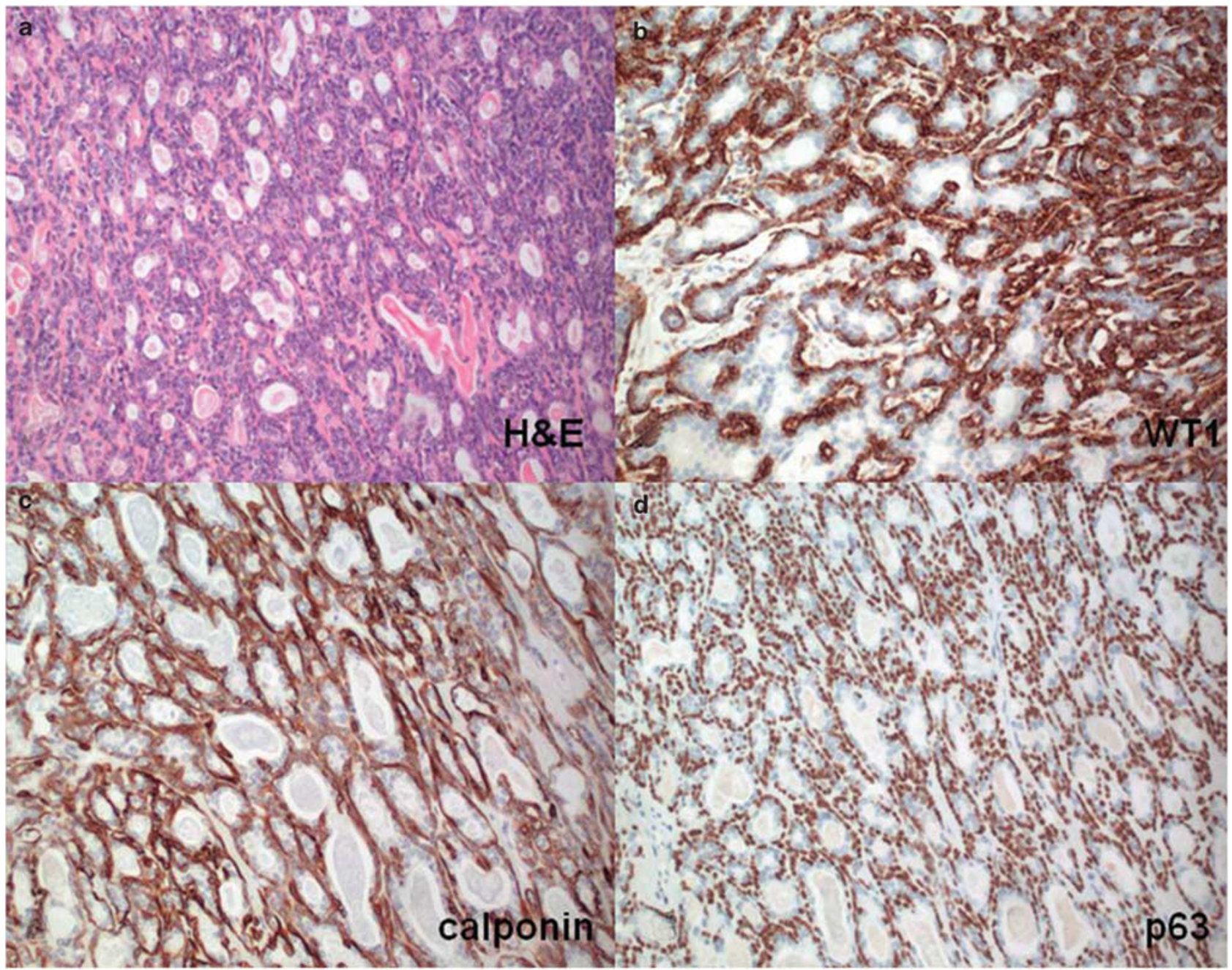

Figure 2 Hematoxylin and eosin image of luminal and abluminal differentiation in a pleomorphic adenoma (a). There is strong expression of abluminal myoepithelial cells for WT1 (b), calponin (c) and p63 (d) with an absent staining of luminal epithelial cells.

mucoepidermoid carcinomas. At present, calponin and p63 are regarded as the most reliable neoplastic myoepithelial markers. ${ }^{18}$

The WT1 gene was first recognized as a tumorsuppressor gene and identified by immunohistochemistry in the nucleus of Wilms' tumor and mesothelioma. ${ }^{7}$ Cytoplasmic staining, as described in this report, was considered to be nonspecific. However, it is now recognized that post-translational phosphorylation results in cytoplasmic retention of WT1 where it is involved in translational regulation. ${ }^{6}$ WT1 is described in a wide variety of human malignancies, the majority of which show diffuse and granular cytoplasmic staining. ${ }^{7}$ These findings suggest that WT1 has a role in the carcinogenesis of many cancers. However, as these tumors arise in tissues that do not normally express WT1, it is suggested that WT1 might act as an oncogene rather than as a tumor-suppressor gene. ${ }^{6}$

In agreement with other studies, we found that calponin and p63 stain the normal myoepithelial cell surrounding the acini and intercalated ducts while p63 was also identified in basal duct cells. ${ }^{8,9}$ Our immunohistochemical analysis showed that in the majority of cases, both markers stained the juxtatubular myoepithelial cells. However calponin demonstrated less uniform expression. Except for the myxoid areas, p63 was a more sensitive marker than calponin in the modified and transformed myoepithelium, but lack of immunoreactivity was not uncommon and few cases showed positive staining in $>50 \%$ of the cells. An exception was the transformed squamous areas, which were consistently highlighted by p63.

In this study, WT1 proved to be a more reliable and sensitive marker of neoplastic myoepithelial cells. In comparison with the other two markers, staining was stronger and more consistent both within the myoepithelial-like and modified myoepithelial cells. The solid proliferation of epithelioid cells and basaloid cribriform areas was also vividly highlighted by WT1. Staining within squamous nests, however, was patchy and limited to the periphery. Squamous differentiation is not an infrequent finding in pleomophic adenomas. ${ }^{19}$ 


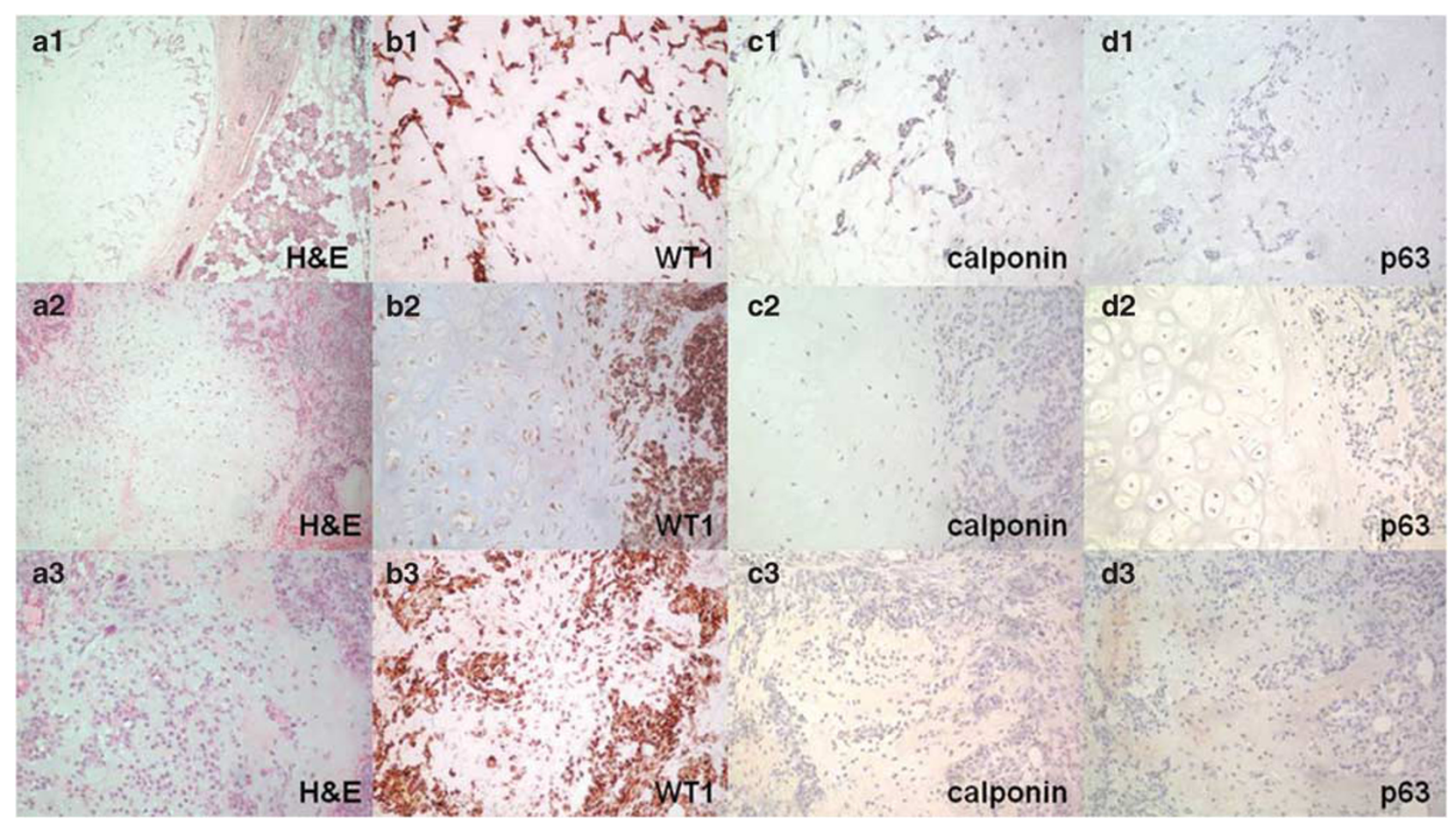

Figure 3 Staining of the modified neoplastic myoepithelium with WT1 (b1-b3), calponin (c1-c3) and p63 (d1-d3). Strong cytoplasmic expression for WT1 is seen in myxoid (b1), cartilaginous (b2) and plasmacytoid (b3) cells with an absent staining for calponin and p63 in the corresponding sections. H\&E stain is shown in a1-a3.
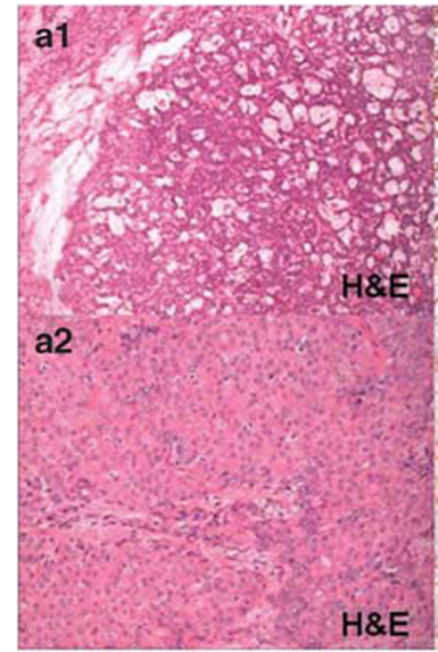

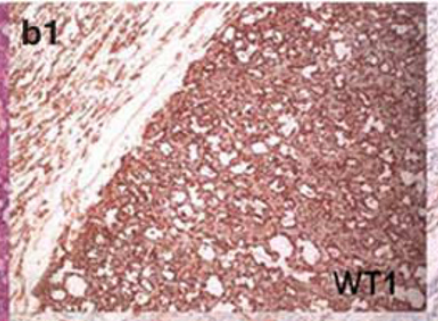

b2

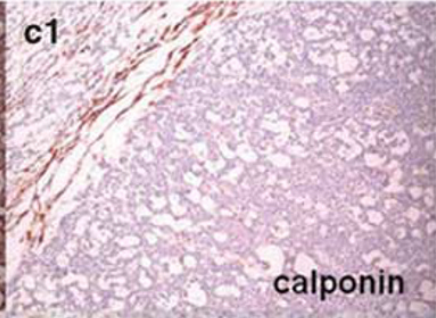

c2

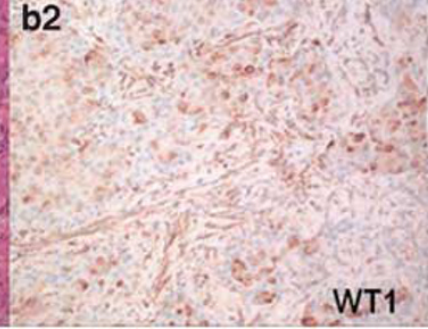

d1

d2

Figure 4 Staining of the transformed neoplastic myoepithelium with WT1 (b1-b2), calponin (c1-c2) and p63 (d1-d2). Cytoplasmic expression for WT1 is seen in the basaloid cribriform (b1) and epithelioid (b2) areas with absent staining for calponin and p63 in corresponding sections. H\&E stain is shown in a1-a2.

The presence of increasing numbers of tonofilaments and well-developed desmosomes in myoepithelial cells before fully developed squamous change $^{20}$ indicates myoepithelial derivation. p63 stains differentiated squamous cells, and this may explain the strong and consistent staining of these cells in pleomorphic adenomas. The pattern of WT1 immunoreactivity, highlighting peripheral cells of the squamous islands, supports the ultrastructural findings of myoepithelial differentiation in these cells, with negative WT1 staining in differentiated squamous cells.

There was no staining of myoepithelial cells with WT-1 in the normal salivary gland tissue. This expression in the neoplastic but not in the normal myoepithelium is also seen with S100, vimentin and GFAP and likely reflects immunophenotypic modification associated with neoplastic transformation. ${ }^{2}$

Many of the myoepithelial immunohistochemical markers are directed against the structural components 


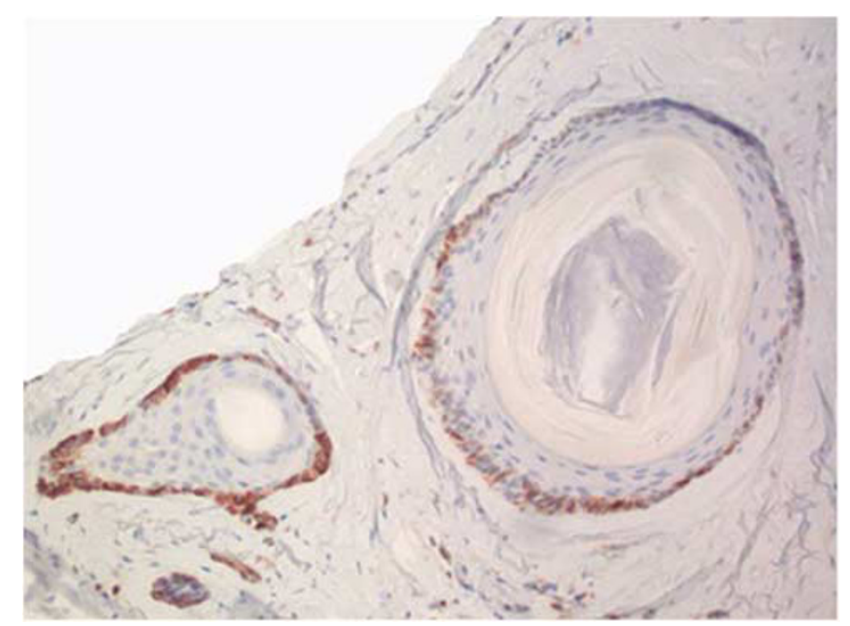

Figure 5 Immunohistochemical staining for WT1 in the transformed squamous islands showing expression in peripheral cells.

of the cell. The introduction of novel stains targeting molecular events, such as WT1, may elucidate the histogenesis of myoepithelial-rich salivary glands neoplasms. WT1 is involved in bidirectional epithelial-mesenchymal transition and its expression in the neoplastic myoepithelium of pleomorphic adenomas could explain their morphological appearance.

In conclusion, we have shown that WT1 is a reliable and specific marker of neoplastic myoepithelial cells in pleomorphic adenomas. If the molecular events that are associated with this expression are restricted to pleomorphic adenomas, then the identification of WT1-immunoreactive cells in salivary gland tumors may be a useful diagnostic tool in surgical and cytological practice. Further studies exploring the expression of WT-1 in other salivary gland tumors are required.

\section{Acknowledgement}

This work was completed as part of the study for the MSc Cellular Pathology degree at the University of Westminster, London.

\section{Disclosure/conflict of interest}

The authors declare no conflict of interest.

\section{References}

1 Norberg L, Stratis M, Dardick I. Quantitation and localization of cycling tumor cells in pleomorphic adenomas and myoepitheliomas: an immunohistochemical analysis. J Oral Pathol Med 1997;26:124-128.

2 Savera AT, Zarbo RJ. Defining the role of myoepithelium in salivary gland neoplasia. Adv Anat Pathol 2004;11:69-85.
3 Lakhani SR, O'Hare MJ. The mammary myoepithelial cell-Cinderella or ugly sister? Breast Cancer Res 2001;3:1-4.

4 Adriance MC, Inman JL, Petersen OW, et al. Myoepithelial cells: good fences make good neighbors. Breast Cancer Res 2005;7:190-197.

5 Nagel H, Laskawi R, Eiffert H, et al. Analysis of the tumour suppressor genes, FHIT and WT-1, and the tumour rejection genes, BAGE, GAGE-1/2, HAGE, MAGE-1, and MAGE-3, in benign and malignant neoplasms of the salivary glands. J Clin Pathol: Mol Pathol 2003;56:226-231.

6 Hohenstein P, Hastie ND. The many facets of the Wilms' tumour gene, WT1. Hum Mol Genet 2006;15: R196-R201.

7 Nakatsuka S, Oji Y, Horiuchi T, et al. Immunohistochemical detection of WT1 protein in a variety of cancer cells. Mod Pathol 2006;19:804-814.

8 Bilal H, Handra-Luca A, Bertrand JC, et al. P63 is expressed in basal and myoepithelial cells of human normal and tumor salivary gland tissues. J Histochem Cytochem 2003;51:133-139.

9 Savera AT, Gown AM, Zarbo RJ. Immunolocalization of three novel smooth muscle-specific proteins in salivary gland pleomorphic adenoma: assessment of the morphogenetic role of myoepithelium. Mod Pathol 1997;10:1093-1100.

10 Savera A, Zarbo R, Yaziji H, et al. Assessment of p63 as a myoepithelial marker using salivary gland pleomorphic adenoma. Mod Pathol 2003;16:222A.

11 Furuse C, Sousa SO, Nunes FD, et al. Myoepithelial cell markers in salivary gland neoplasms. Int J Surg Pathol 2005;13:57-65.

12 Zarbo RJ, Regezi JA, Batsakis JG. S-100 protein in salivary gland tumors: an immunohistochemical study of 129 cases. Head Neck Surg 1986;8:268-275.

13 Jones H, Moshtael F, Simpson RHW. Immunoreactivity of alpha smooth muscle actin in salivary gland tumours: a comparison with $\mathrm{S} 100$ protein. J Clin Pathol 1992;45:938-940.

14 Khan HJ, Baumal R, Marks A, et al. Myoepithelial cells in salivary gland tumors. Arch Pathol Lab Med 1985; 109:190-195.

15 Nishimura T, Furukawa M, Kawahara E, et al. Differential diagnosis of pleomorphic adenoma by immunohistochemical means. J Laryngol Otol 1991; 105:1057-1060.

16 Hirano T, Gluckman JL, deVries EJ. The expression of alpha vascular smooth-muscle actin in salivary gland tumors. Arch Otolaryngol Head Neck Surg 1990;116: 692-696.

17 de Lima Navarro R, Martins MT, de Araujo VC. Maspin expression in normal and neoplastic salivary gland. J Oral Pathol Med 2004;33:435-440.

18 Cheuk W, Chan JKC. Salivary gland tumours. In: Fletcher CDM (ed). Diagnostic Histopathology of Tumors, 3rd edn. Churchill Livingstone, Elsevier: Philadelphia, 2007, pp 239-252.

19 Dardick I, van Nostrand AW, Phillips MJ. Histogenesis of salivary gland pleomorphic adenoma (mixed tumor) with an evaluation of the role of the myoepithelial cell. Hum Pathol 1982;13:62-75.

20 Dardick I, Van Nostrand AW, Jeans MT, et al. Pleomorphic adenoma, I: ultrastructural organization of 'epithelial' regions. Hum Pathol 1983;14:780-797. 